\title{
STUDENT CARE PATTERNS IN INTEGRATED ISLAMIC BOARDING SCHOOL BINA AMAL SEMARANG
}

\author{
AJI SOFANUDIN*, RAKHMAWATIPRIHASTUTY*, AND HAMIDULLOH IBDA***
}

"Balai Penelitian dan Pengembangan Agama Semarang, JI Untung Suropati Kav 69-70 Ngaliyan Semarang, "Fakultas IImu Pendidikan UNNES, JI Sekaran Gunung Pati Semarang 50229, "** STAINU Temanggung, JI Suwandi Suwardi KM 1 Kabupaten Temanggung. Email: ajisofan@gmail.com

\begin{abstract}
This research aims to determine caring patterns for student in an integrated Islamic boarding school (SMIT) Bina Amal Semarang. Teacher act as parents in this caring activity to conduct supervision, guidance, discipline, giving reward and punishment. SMIT Bina Amal Semarang is an integrated boarding Islamic school which consists of junior and senior high schools. By using qualitative approach, the research found that caring patterns at these schools were developed in a democratic pattern of pesantren model. All students of the schools were automatically deemed as "santri"(students) of the "pesantren" Bina Amal. Supervision, guidance, discipline, reward and punishment implemented at the Bina Amal Semarang schools were carried out by caregivers along with a clear organizational management consisting of three coordinators: Islamic culture and discipline coordinator, tahsin tahfiz coordinator, and academic coordinator. The rules were strictly enforced through student management guidelines that contain academic guidelines and dormitory rules. Learning system was integrated between school and dormitory programmes.
\end{abstract}

Key Words: Bina Amal, care patterns, democratic, santri

\section{POLA ASUH PESERTA DIDIK PADA SEKOLAH MENENGAH ISLAM TERPADU (SMIT) BINA AMAL SEMARANG}

\begin{abstract}
Abstrak
Penelitian ini bertujuan untuk mengetahui pola asuh peserta didik Sekolah Menengah Islam Terpadu (SMIT) Bina Amal Semarang. Pola asuh merupakan cara guru sebagai orang tua dalam melakukan pengawasan, bimbingan, disiplin, pemberian hadiah dan hukuman yang diterapkan kepada peserta didik. SMIT Bina Amal Semarang merupakan Sekolah Islam Terpadu yang dikelola dengan sistem asrama (boarding school) terdiri atas jenjang SMP dan SMA. Dengan menggunakan pendekatan kualitatif temuan penelitian menunjukkan bahwa pola asuh peserta didik pada SMIT Bina Amal Semarang menerapkan pola demokratis model pesantren. Seluruh peserta didik SMIT Bina Amal otomatis adalah "santri" pada "pesantren" Bina Amal. Pengawasan, bimbingan, disiplin, pemberian hadiah dan hukuman yang diterapkan di Bina Amal Semarang dilakukan oleh pengasuh beserta organ struktur organisasi yang jelas: korbid budaya Islami dan kedisiplinan, korbid tahsin tahfiz, dan korbid akademik. Aturan diterapkan secara ketat melalui pedoman pengelolaan peserta didik yang berisi pedoman akademik dan tata kehidupan asrama. Pembelajaran peserta didik terintegrasi antara kegiatan pembelajaran sekolah dan kegiatan santri di asrama.
\end{abstract}

KatA KunCI: Bina Amal, demokratis, pola asuh, santri

* Naskah diterima Januari 2021, direvisi Maret 2021, dan disetujui untuk diterbitkan Mei 2021

Dialog, 44(1), 2021, 89-99

https://jurnaldialog.kemenag.go.id,p-ISSN: 0126-396X,e-ISSN: 2715-6230

This is open access article under CC BY-NC-SA-License

(https://creativecommons.org/license/by-nc-sa/4.0/)

Dialog Vol. 44, No.1, JunI 2021 


\section{A. Pendahuluan}

Sepuluh lima belas tahun belakangan ini muncul sekolah yang menggunakan label "Islam Terpadu" yang banyak diminati masyarakat muslim kelas menengah (Suyatno, 2015) (Sofanudin, 2019b). Sekolah Islam Terpadu tersebut sebagian mengusung model pembelajaran full day school dan sebagian menerapkan boarding school atau sistem asrama (Muzayanah \& Wahab, 2019). Model sekolah ini merupakan kelanjutan dinamika sejarah Pendidikan Islam di Indonesia. Pola asuh yang diterapkan sekolah model ini tentu memiliki karakteristik yang berbeda dengan sekolah umum. Fungsi sekolah tidak semata untuk pendidikan tetapi memiliki fungsi pewarisan nilai. Fungsi pendidikan terefleksi dalam bentuk transfer of knowledge, sementara fungsi pewarisan nilai adalah fungsi dakwah, fungsi misi dan penyebarluasan suatu paham/nilai tertentu melalui lembaga pendidikan. Dalam sejarah, pesantren, madrasah, dan sekolah Islam merupakan lembaga pendidikan Islam yang memiliki peran ganda tersebut. Ketiganya masih eksis hingga sekarang ini (Sofanudin, 2019a).

Sekolah atau madrasah yang menyelenggarakan sistem berasrama atau boarding model pesantren banyak bermunculan (Sofanudin, 2012). Beberapa satuan pendidikan mengusung label: Islamic Boarding School, Integrated Islamic Boarding School, Muhammadiyah Boarding School (MBS), dan sebagainya. Dengan menggunakan label tersebut, lembaga tersebut memosisikan diri sebagai sekolah/madrasah unggulan. Pendidikan model pesantren saat ini menjadi tren pengelolaan pendidikan, salah satunya alasannya untuk mempermudah sebagai lembaga pembentuk karakter (Syafe'i, 2017). Dengan sistem asrama pengelolaan peserta didik atau santri menjadi lebih terarah. Hakikat pendidikan nasional berfungsi mengembangkan kemampuan dan membentuk watak serta peradaban bangsa yang bermartabat dalam rangka mencerdaskan kehidupan bangsa (UU Sisdiknas, Pasal 3). Oleh karena itu, dibutuhkan pola asuh yang tepat dalam kerangka mencerdaskan kehidupan bangsa. Pola asuh merupakan bagian dari proses pendidikan yang berupaya memberikan bimbingan dan perlindungan pada anak dengan cara memberikan perhatian, waktu dan dukungannya untuk memenuhi kebutuhan fisik, mental dan sosial anak di masa pertumbuhannya.

Penelitian sebelumnya tentang SIT banyak mengulas tentang sejarah dan ideologi SIT (Suyatno, 2013), tingginya animo masyarakat terhadap SIT (Suyatno, 2015), manajemen SIT (Wahab, 2018), dan tipologi kurikulum SIT (Sofanudin, 2019b). Riset tentang pengasuhan lebih banyak pada kelembagaan pesantren (Achmad Dudin, 2020). Penelitian ini bertujuan untuk mengetahui model pola asuh yang diterapkan pada sekolah berasrama pada SMIT Bina Amal Semarang.

Secara operasional penelitian ini bertujuan untuk mengetahui bagaimana (1) pengelolaan santri SMIT Bina Amal Semarang, (2) bagaimana pengasuh mengatur kegiatan asrama terkait pengawasan, bimbingan, disiplin, pemberian hadiah dan hukuman yang diterapkan di SMIT Bina Amal Semarang, (3) bagaimana implementasi pola asuh peserta didik pada SMIT Bina Amal Semarang.

Pola asuh yang diterapkan di sekolah berasrama meniru model pesantren. Meskipun demikian banyak sekolah asrama yang tidak memiliki izin sebagai pondok pesantren. UU Nomor 18 Tahun 2019 tentang pesantren, Pasal 5 (2) menyebutkan ada lima unsur dalam pesantren (1) kiai, (2) santri yang bermukim di pesantren, (3) pondok atau asrama, (4) masjid atau musholla dan (5) kajian kitab kuning atau dirasah Islamiah dengan pola pendidikan muallimin. Belum turunnya izin pesantren bisa jadi karena persoalan pada pembelajaran kitab kuning dan/atau legitimasi kiai. Meskipun demikian, pada praktiknya banyak lembaga pendidikan yang menyelenggarakan pendidikan model pesantren. Pola asuh mencakup beragam aktivitas yang bertujuan agar anak dapat berkembang secara optimal dan dapat bertahan hidup dengan baik. Tugas kepengasuhan pada dasarnya untuk membimbing dan mengarahkan kepribadian anak, terutama dalam kaitannya dengan ibadah kepada Tuhan Yang Maha Esa.

\section{B. Kajian Teori}

Karel A Steenbrink mengkaji secara serius perkembangan lembaga pendidikan Islam: pesantren, madrasah dan sekolah (Steenbrink, 1986). Meskipun teorinya tentang pesantren akan bubar dengan hadirnya madrasah, madrasah akan 
tutup dengan munculnya sekolah Islam tidak terbukti. Namun, Steenbrink mampu memotret dinamika pendidikan Islam secara komprehensif. Zamaksyari Dhofier mampu mengungkap lebih dalam lagi tentang tradisi yang ada di pesantren (Dhofier, 1994).

Selain mendidik ilmu-ilmu agama, santri juga diajarkan ilmu umum. Model pesantren yang mengajarkan kemandirian, belajar ilmu, dan belajar hidup. Pola asuh santri yang merepresentasi tradisi ngangsu kawruh (menimba ilmu) dengan kiai inilah yang menjadikan santri memiliki kompetensi plus dibandingkan lulusan pendidikan formal. Jika kiai memiliki sawah atau tegal, maka santri ikut mencangkul, menanam, dan memanen. Jika kiai memiliki toko, usaha peternakan, percetakan, jasa travel, koperasi, maka santri ikut mendapat berkah karena secara langsung belajar bisnis dan manajemen. Santri ketika di pesantren sangat mandiri, sebab mereka memasak, mencuci pakaian dan peralatan dapur, dan melakukan kegiatan dapur secara pribadi. Santri di ponpes salaf juga terbiasa belanja sembako di pasar. Wajar jika orang Jawa menyebut ponpes sebagai "penjara suci" karena sangat jauh dari gemerlap kehidupan dunia (Ibda, 2019).

Ada semangat sistem pendidikan pesantren diadopsi oleh sekolah/madrasah berasrama. Hal inilah yang menjadikan sekolah/madrasah berasrama memiliki keunggulan pada santri yang mendapat pola asuh secara komplit dibandingkan pola asuh orangtuanya sendiri. Sekolah dan madrasah saat ini juga banyak yang mengembangkan model pesantren. Bahkan animo masyarakat terhadap madrasah yang terintegrasi dengan pesantren lebih tinggi. Terbukti PPDB pada madrasah berbasis pesantren memiliki peserta didik lebih banyak dibandingkan madrasah biasa.

Sekolah dan madrasah berbasis asrama menjadi tren pengelolaan pendidikan dewasa ini. Dengan sistem boarding pendidik lebih mudah membimbing dan mengawasi perkembangan peserta didik. Selain itu juga melatih kemandirian peserta didik. Madrasah dan sekolah berasrama (boarding school) merupakan lembaga pendidikan berciri agama dan keagamaan yang mengadopsi sistem pendidikan pesantren yang telah lama berkembang di Indonesia. Kini madrasah dan sekolah berasrama juga memiliki andil yang sangat strategis dalam membentuk watak bangsa
Indonesia yang religius dan taat beribadah kepada Tuhan Yang Maha Kuasa.

Pola asuh merupakan serangkaian sikap yang ditunjukkan oleh orang tua kepada anak untuk menciptakan iklim emosi yang melingkupi interaksi antara orang tua dan anak (Lestari, 2014). Menurut Shohib, konsep pola asuh adalah upaya yang digunakan untuk memahami, menginterprestasi dan menemukan maknamakna yang terkandung dalam mengembangkan dasar-dasar nilai peserta didik. Pengupayaan dilakukan melalui pelatihan, pembiasaan, dan penyadaran kepada peserta didik (Fitriyani, 2015) (Shochib, 1997). Djamarah menyatakan bahwa konsep pola asuh adalah membangun komunikasi yang harmonis, dan menerapkan fungsi pendidikan untuk menumbuhkan potensi santri/ anak sebagai wahana untuk mentransfer nilainilai dan agen tranformasi kebudayaan (Padjrin, 2016) (Adawiah, 2017) (Fitriyani, 2015).

Pola asuh peserta didik yang dijadikan teori ini adalah pola asuh peserta didik yang mengulas jenis pola asuh, yaitu:(1) otoriter; (2) demokratis; (3) permisif; dan (4) pengabaian/pembiaran. Pola asuh terdiri atas empat aspek yang penting yaitu: pengawasan, komunikasi, kedisiplinan serta hukuman dan penghargaan. Keempat aspek tersebut merupakan substansi yang penting diperhatikan dalam pola pengasuhan santri di pesantren (Achmad Dudin, 2020).

Pertama, pola asuh otoriter yang ditandai dengan cara mengasuh anak dengan aturanaturan yang ketat, suka memaksa anak untuk berperilaku seperti dirinya (orang tua), kebebasan untuk bertindak atas nama diri sendiri dibatasi. Kedua, pola asuh demokratis, ditandai dengan adanya pengakuan orang tua terhadap kemampuan anak, anak diberi kesempatan untuk tidak selalu tergantung pada orang tua. Ketiga, pola asuh permisif, ditandai dengan cara orang tua mendidik anak yang cenderung bebas, anak dianggap sebagai orang dewasa atau muda, ia diberi kelonggaran seluas-luasnya untuk melakukan apa saja yang dikehendaki (Muallifah, 2009). Keempat, pola asuh pembiaran, pengabaian atau kelalaian ditandai dengan kelalaian orang tua. Dalam pola asuh ini, orang tua sama sekali tidak terlibat dengan apa pun yang terkait dengan anak. Orang tua tidak menuntut, tak responsif, dan minim komunikasi (Adawiah, 2017).

Sekolah dan madrasah berasrama telah 
melakukan pola asuh dengan baik kepada peserta didik untuk menjadi manusia yang bertakwa kepada Allah SWT, berakhak mulia, mempunyai integritas pribadi yang utuh, mandiri dan mempunyai kualitas intelektual. Di dalam madrasah dan sekolah berasrama para peserta didik diasuh untuk belajar hidup bermasyarakat, berorganisasi, melakukan pembiasaan akhlakul karimah, disiplin dalam belajar dan beribadah. Pada umumnya terdapat bidang/biro/seksi yang bertanggung jawab terhadap keseharian pola asuh santri.

Peran pengasuh adalah mengontrol dan mengawasi anak serta hubungan antara keduanya lebih dekat. Hal ini bertujuan untuk melatih kemandirian peserta didik. Pola asuh yang diterapkan di asrama cenderung bersifat otoriter atau berpusat pada satu figur saja. Melalui gaya pembinaaan yang seperti ini diharapkan peserta didik akan patuh dan berkembang ke arah yang diharapkan oleh sekolah berasrama. Gaya pola asuh yang otoriter berpengaruh terhadap kondisi santri yang tinggal di pondok pesantren bila dibandingkan dengan pola asuh yang lainnya seperti permisif dan demokratis. Pengaruh yang menonjol salah satunya terhadap kedisiplinan santri. Oleh sebab itu, pembina harus membiasakan santri untuk mengikuti serangkaian kegiatan pondok pesantren dan menaati peraturan yang berlaku (Ali, Imtihana, Ismail, \& Zaini, 2018).

Pola asuh di pesantren tentu memiliki keunikan dibandingkan di sekolah umum. Hubungan antara pengasuh (kiai) dengan santri sangat erat. Saat ini berkembang new santri, di mana pemerolehan ilmu agama tidak selalu melalui pesantren. Bahkan berkembang pula lembaga pendidikan yang mengusung tema kuttab, yang secara substansi mirip dengan pesantren (Sofanudin, 2021).

Dalam aspek pola asuh peserta didik, terdapat berbagai persoalan di antaranya, untuk aspek pengawasan hasil penelitian Nikmah Sofia Afiati menunjukkan bahwa peserta didik asrama di pesantren rentan dengan keadaan rendah pengawasan karena jumlah ustaz dan ustazah yang terbatas. Pihak pesantren sendiri tidak mampu untuk melakukan pengawasan dan kontrol secara maksimal terhadap santrinya sehingga sering terjadi pelanggaran (Afiati, 2018). Selain itu, penerapan peraturan di pesantren tidak menjadi jaminan bahwa disiplin dapat terwujud dengan baik. Pada kenyataannya masih banyak pelanggaran yang dilakukan peserta didik baik ketika jam sekolah maupun ketika mengikuti kegiatan di asrama (Afiati, 2018).

Pada aspek pemberian hadiah dan hukuman, maka menurut Sardiman, bahwa salah satu pendekatan yang dapat meningkatkan perhatian dan membuat peserta didik lebih aktif adalah dengan memberikan hadiah berupa penghargaan serta pujian dan hukuman. Pujian merupakan dorongan bagi seseorang untuk belajar lebih giat, pujian selalu berhubungan dengan prestasi yang baik (Sardiman, 2007). Keempat aspek tersebut merupakan substansi yang penting diperhatikan dalam aspek pola asuh peserta didik di madrasah dan sekolah berasrama.

\section{Metode Penelitian}

Penelitian ini dilakukan pada peserta didik Sekolah Menengah Islam Terpadu (SMIT) Bina Amal. SMIT Bina Amal terdiri atas SMP IT dan SMA IT Bina Amal. Pengumpulan data dilakukan dengan observasi, wawancara, dan telaah dokumen. Waktu pengumpulan data dilakukan selama sepuluh hari (3 s.d 12 Juli 2020). Observasi dilakukan pada SMIT Bina Amal Semarang. Selain itu, juga dilakukan pada asrama (pesantren) Bina Amal Semarang. Wawancara dilakukan terhadap Kepala SMP IT, guru SMP IT, Waka Kesiswaan SMA IT, guru SMA IT dan Pengasuh (Kepala Asrama) Bina Amal. Telaah dokumen dilakukan terhadap hasil penelitian terdahulu tentang Sekolah Islam Terpadu serta profil SMP IT, SMA IT dan Asrama Bina Amal Semarang. Selain itu, pengumpulan data penelitian ini juga dengan menggunakan angket yang digunakan untuk memperoleh data dari siswa/santri.

Penelitian ini menggunakan mix methods yaitu pendekatan kualitatif dan kuantitatif. Pendekatan kualitatif dilakukan melalui pendalaman terhadap pola asuh peserta didik di asrama pada sekolah berasrama Bina Amal. Pendekatan kuantitatif untuk membantu menjawab persoalan yang bersifat kuantitas. Instrumen pada penelitian ini adalah peneliti sendiri. Teknik analisis data menggunakan empat komponen di mana keempat komponen tersebut merupakan proses siklus dan interaktif dalam sebuah penelitian. Keempat komponen tersebuat ialah reduksi data, penyajian data, penafsiran dan penyimpulan data. 
Pembahasan dalam pola asuh peserta didik di asrama pada SMIT Bina Amal meliputi: sistem pola asuh, jenis pola asuh, dan aspek pola asuh peserta didik. Pembahasan profil pola asuh peserta didik, meliputi pengasuh, peserta didik, peraturan, alat hukuman dan hadiah, penegakan aturan, pendisiplinan dan hukuman, serta pembentukan karakter, dan hasil pengasuhan. Pembahasan jenis pola asuh peserta didik mencakup empat teori pola asuh yaitu: (1) pola asuh otoriter; (2) pola asuh demokratis; (3) pola asuh permisif, dan (4) pola asuh pembiaran.

Secara operasional penelitian ini dilakukan sebagai berikut:

Tabel 1

Dimensi, Indikator, Sumber Data, Teknik

\begin{tabular}{|c|c|c|c|}
\hline Dimensi & Indikator & $\begin{array}{l}\text { Sember } \\
\text { Data }\end{array}$ & $\begin{array}{l}\text { Teknik } \\
\text { Penggalian } \\
\text { Data }\end{array}$ \\
\hline $\begin{array}{l}\text { Profil } \\
\text { Pola } \\
\text { asuh } \\
\text { Peserta } \\
\text { Didik }\end{array}$ & $\begin{array}{l}\text { Program, } \\
\text { Pengasuh, peserta } \\
\text { didik, peraturan, } \\
\text { alat hukumandan } \\
\text { hadiah, penegakan } \\
\text { aturan, } \\
\text { pendisiplinandan } \\
\text { hukuman serta } \\
\text { manajemen pola } \\
\text { asuh }\end{array}$ & Pengasth & $\begin{array}{l}\text { Telaah } \\
\text { dokumen }\end{array}$ \\
\hline \multirow[t]{3}{*}{$\begin{array}{l}\text { Jenis } \\
\text { Pola } \\
\text { Pola } \\
\text { asth } \\
\text { Peserta } \\
\text { Didik }\end{array}$} & Demokratis & $\begin{array}{l}\text { Pengasth } \\
\text { dan } \\
\text { peserta } \\
\text { didik } \\
\text { Pengastuh } \\
\text { dan } \\
\text { peserta } \\
\text { didk }\end{array}$ & $\begin{array}{l}\text { Wawancara } \\
\text { dan } \\
\text { peryebaran } \\
\text { angket } \\
\text { Wawancara } \\
\text { dan } \\
\text { pernyebaran } \\
\text { angket }\end{array}$ \\
\hline & Permisif & $\begin{array}{l}\text { Pengasuh } \\
\text { dan } \\
\text { peserta } \\
\text { didk }\end{array}$ & $\begin{array}{l}\text { Wawancara } \\
\text { dan } \\
\text { pernyebaran } \\
\text { angket }\end{array}$ \\
\hline & Pembiaran & $\begin{array}{l}\text { Pengasuh } \\
\text { dan } \\
\text { peserta } \\
\text { didk }\end{array}$ & $\begin{array}{l}\text { Wawancara } \\
\text { dan } \\
\text { pernyebaran } \\
\text { angket }\end{array}$ \\
\hline \multirow{4}{*}{$\begin{array}{l}\text { Aspek } \\
\text { Pola } \\
\text { Pola } \\
\text { astih } \\
\text { Peserta } \\
\text { Didik, }\end{array}$} & Pengawasan & $\begin{array}{l}\text { Pengastuh } \\
\text { dan } \\
\text { peserta } \\
\text { didk }\end{array}$ & $\begin{array}{l}\text { Wawancara } \\
\text { dan } \\
\text { penyebaran } \\
\text { angket }\end{array}$ \\
\hline & Bimbingan & $\begin{array}{l}\text { Pengasuh } \\
\text { dan } \\
\text { peserta } \\
\text { didk }\end{array}$ & $\begin{array}{l}\text { Wawancara } \\
\text { dan } \\
\text { pernyebaran } \\
\text { angket }\end{array}$ \\
\hline & Disiplin & $\begin{array}{l}\text { Pengasuh } \\
\text { dan } \\
\text { peserta } \\
\text { didk }\end{array}$ & $\begin{array}{l}\text { Wawancara } \\
\text { dan } \\
\text { pernyebaran } \\
\text { angket }\end{array}$ \\
\hline & $\begin{array}{l}\text { Hadiah dan } \\
\text { Hukuman }\end{array}$ & $\begin{array}{l}\text { Pengasth } \\
\text { dan } \\
\text { peserta } \\
\text { didk }\end{array}$ & $\begin{array}{l}\text { Wawancara } \\
\text { dan } \\
\text { penyebaran } \\
\text { angket }\end{array}$ \\
\hline
\end{tabular}

Sumber: Achmad Dudin, dkk 2020

\section{Hasil dan Pembahasan}

Ada kecenderungan sekolah Islam dan madrasah menerapkan sistem asrama (boarding school). Beberapa sekolah di Kota Semarang yang menyelenggarakan asrama atau boarding adalah SMP-SMA IT Bina Amal, SMP-SMA Semesta, sekolah Nasima. Beberapa Madrasah Aliyah juga menerapkan sistem boarding di antaranya adalah MAN 1 Semarang (tidak semua peserta didik), MTs MA Al-Wathoniyah, MA Al-Asror, MA Askhabul Kahfi (Wawancara Kasi Pendma, 4/7/ 2020). SMIT Bina Amal merupakan salah satu sekolah yang menerapkan sistem sekolah berasrama.

Bina Amal Boarding School merupakan bagian dari Sekolah Islam Terpadu. Di Kota Semarang terdapat TK, SD, SMP dan SMA Bina Amal. Lokasi TK dan SD berada di pusat kota yakni di Jl Kiai Saleh Semarang. Sementara lokasi SMP dan SMA berada di Semarang bagian selatan yakni Jl Raya Gunung Pati-Ungaran Km 1,5 Plalangan Gunungpati Kota Semarang. SMP dan SMA Bina Amal mengusung brand "Islamic Integrated Boarding School". Meski berbeda tingkatan, lokasi sekolah ini menyatu. Lokasi dipisahkan antara asrama putra dan asrama untuk putri.

Tahun 2008 Yayasan Wakaf Bina Amal mendirikan sekolah menengah pertama Islam Terpadu (SMP IT) dengan menerapkan model asrama (boarding school), dan pada tahun 2016 mendirikan sekolah menengah atas Islam Terpadu (SMA IT) dan menerapkan model asrama juga. Manajemen peserta didik pada SMIT Bina Amal terintegrasi antara pembelajaran sekolah dan pembelajaran di asrama.

Pada pengelolaan asrama terdapat kepala asrama putra dan putri yang berperan sebagai pengasuh atau penanggung jawab asrama. Penanggung jawab asrama adalah orang yang memahami agama (ahli agama), biasa dipanggil ustaz/ustazah (kiai dan bu nyai) yang wajib tinggal (berdomisili) bersama dengan para santri di asrama. Penunjukan pengasuh asrama dilakukan oleh Yayasan.

Kepala asrama (pengasuh) dibantu oleh sekretaris asrama dengan tiga koordinator bidang: (1) koordinator bidang budaya Islam dan kedisiplinan, (2) koordinator bidang tahsin tahfiz SMP dan SMA, dan (3) koordinator bidang akademik. Masing-masing koordinator membawahi penanggung jawab bidang. Pada 
korbid satu ada pj bina pribadi Islami, pj kedisiplinan, dan pj life skill. Pada bidang tiga ada pj ulum diniyah, pj bimbel dan pj bahasa.

Kepala asrama dibantu oleh seorang sekretaris dengan membawahi tiga korbid: Budaya Islami dan Kedisiplinan, TTQ, dan akademik. Korbid budaya Islami dan kedisiplinan terdiri atas bidang: BPI, kedisiplinan dan life skill. TTQ terbagi menjadi TTQ untuk SMP dan SMA. Bidang akademik meliputi ulum diniyah, bimbel dan Bahasa. Selain itu, dibentuk pula wali asrama untuk masing-masing kelas: kelas 7, kelas 8, dan kelas 9 untuk peserta didik SMP dan wali asrama untuk kelas X, XI, dan XII untuk peserta didik SMA. Pada masing-masing wali asrama dibantu pendamping asrama.

Korbid budaya Islami dan kedisiplinan mempunyai tugas sebagai berikut:

1. Mengembangkan dan meningkatkan budaya Islami di asrama.

2. Merancang program pendidikan karakter anak.

3. Merancang kegiatan keasramaan.

4. Mengkoordinir guru asrama, guru pendamping asrama, pj kedisiplinan agar bisa menjalankan tugas-tugasnya.

5. Menyusun program yang berhubungan dengan peringatan hari besar Islam.

6. Menerapkan disiplin di segala aspek di asrama berdasarkan peraturan dan tata tertib santri yang berlaku.

7. Mengayomi para siswa untuk mewujudkan ketenangan di asrama.

8. Bertindak tegas terhadap pelanggaran Tata Tertib yang dilakukan siswa

Korbid TTQ bertugas sebagai berikut:

1. Menyusun program kerja bidang tahsin dan tahfiz

2. Menyusun rencana anggaran bidang tahsin dan tahfiz

3. Menentukan ustaz/ustazah pengampu tahsin dan tahfiz

4. Mengoordinasi pelaksanaan kegiatan tahsin

5. Mengoordinasi pelaksanaan kegiatan tahfiz Qur'an dan Hadist

6. Mengoordinasi evaluasi kegiatan tahsin dan tahfiz

7. Melaporkan kegiatannya setiap bulan kepada waka 4
Korbid KBM siswa atau akademik bertugas sebagai berikut:

1. Mengembangkan konsep, kurikulum, metodelogi, sistem pembelajaran, serta evaluasi dan sumber belajar KBM asrama

2. Menyusun program akademik

3. Menyusun rencana anggaran bidang akademik

4. Memberikan masukan-masukan kepada sekolah tentang kebutuhan guru beserta kualifikasinya

5. Menyusun jadwal pelajaran di asrama

6. Mengoordinasikan penyusunan alat evaluasi hasil belajar

7. Mengoordinasikan kegiatan evaluasi hasil belajar

8. Mengoordinasikan kegiatan remedial dan pengayaan

9. Mengoordinasikan penyusunan sistem penilaian ketuntasan belajar siswa

10. Mengoordinasikan perlombaan-perlombaan bidang studi

Wali asrama adalah guru yang mendapat tugas untuk mendampingi anak di asrama sesuai dengan jumlah anak yang menjadi tugasnya. Ia adalah orang tua sekaligus teman terbaik anak di asrama. Tugas wali asrama dari pukul 14.45 08.20 WIB. Tugas wali asrama sangat banyak yaitu:

1. Mengondisikan dan mendampingi kegiatan anak-anak di asrama dari jam 14.45 sore 08.20 pagi.

2. Memastikan anak sudah masuk asrama jam 21.00 dan masuk kamar (tidur) maksimal jam 22.00 .

3. Melakukan pendampingan dan pembinaan proses tumbuh kembang karakter anak ke arah yang positif.

4. Menciptakan suasana kehidupan asrama yang saling bersaudara dan mencintai karena Allah, nyaman, aman, dan menyenangkan.

5. Membersamai dan memberi semangat kegiatan ibadah, belajar anak, dan kegiatan anak.

6. Menjadi teladan dalam masalah akidah, ibadah, dan akhlak.

7. Menyelesaikan dan memberikan arahan atau nasehat kepada anak yang sedang mengalami permasalahan.

8. Mendorong pembiasaan budaya $\mathrm{K} 3$ di asrama.

9. Mencatat permasalahan dan langkah 
penyelesaiannya di buku kasus.

10. Mengontrol piket asrama

11. Mengikuti agenda rutin rapat asrama, briefing guru dan rapat sekolah/unit,

12. Mengikuti kegiatan hari Krida Guru

13. Membangunkan siswa untuk qiyamullail, sahur dan salat subuh.

14. Membersamai anak melakukan kegiatan zikir alma'tsurot.

15. Jika ada siswa yang sakit, melapor ke petugas UKS dan memastikan kondisi siswa

16. Jika siswa sakit dan tinggal di asrama, melakukan pendampingan (terkait pengawasan obat, pelayanan kebutuhan makan), jika sakit lebih dari 2 hari, mengomunikasikan kepada orangtua untuk dapat dirawat di rumah.

17. Membersamai dan mengontrol siswa saat makan malam dan sarapan pagi (memastikan kedisiplinan dan ketertiban siswa di ruang makan)

18. Menerima dan menyampaikan pesan dari orangtua (jika ada), baik secara langsung ataupun tidak langsung.

19. Mengomunikasikan dan berkoordinasi dengan tim asrama unit yang bersifat teknis

20. Melaporkan dan merekap mutabaah/ perkembangan siswa di asrama secara struktural setiap pekan.

21. Mengunci kamar asrama, memastikan asrama ditinggalkan dalam kondisi aman pada saat jam KBM dan jadwal kepulangan.

22. Memastikan siswa untuk bersegera dan bersiap berangkat ke sekolah serta memimpin apel asrama.

Selain itu terdapat pendamping asrama yaitu guru/pegawai yang bertugas sesuai dengan tupoksinya pada kegiatan sekolah di pagi hari, yang karena bertempat tinggal di asrama mendapat tugas untuk membantu kegiatan keasramaan dan mendampingi proses tumbuh kembang anak.

Tugas pendamping asrama adalah sebagai berikut:

1. Tugas dimulai jam 17.15 sampai 05.30 WIB.

2. Membersamai anak makan malam dan salat maghrib berjemaah.

3. Membantu guru asrama dalam kegiatan budaya al-Quran.

4. Membersamai dan mengondisikan anak untuk melakukan kegiatan salat isya berjemaah.

5. Membantu persiapan kegiatan malam, baik bimbel, KBM malam, mentoring, dan kegiatan asrama yang lain.

6. Membantu membangunkan siswa untuk persiapan salat shubuh berjemaah dan membersamai kegiatan alma'tsurot pagi.

7. Membantu guru asrama untuk mengingatkan anak bersegera mengikuti kegiatan apel asrama.

8. Melakukan pendampingan dan pembinaan proses tumbuh kembang anak ke arah yang positif.

9. Menciptakan suasana kehidupan asrama dan sekolah yang saling bersaudara dan mencintai karena Allah, nyaman, aman, dan menyenangkan.

10. Membersamai dan memberi semangat kegiatan ibadah, belajar anak, dan kegiatan anak.

11. Menjadi teladan dalam masalah akidah, ibadah, dan akhlak.

12. Memberikan arahan atau nasehat kepada anak yang sedang mengalami permasalahan

13. Mendorong pembiasaan budaya $\mathrm{K} 3$ di asrama dan sekolah.

14. Melaporkan kejadian permasalahan anak pada guru asrama.

15. Membantu tugas guru asrama dalam menjalankan amanahnya dengan selalu berkomunikasi dan berkoordinasi

Selain wali asrama dan guru pendamping terdapat juga guru asuh yaitu guru yang mendapat tugas untuk menjadi guru asuh bagi anak sesuai dengan jumlah anak yang disepakati. Tugas guru asuh adalah sebagai berikut:

1. Melakukan pendampingan dan pembinaan proses tumbuh kembang anak ke arah yang positif di sekolah dan lingkungan sekolah.

2. Menjadi teladan dalam masalah akidah, ibadah, dan akhlak.

3. Menjadi teman curhat anak yang menyenangkan.

4. Menyelesaikan dan memberikan arahan atau nasehat kepada anak yang sedang mengalami permasalahan

5. Mengomunikasikan permasalahan anak dan langkah penyelesaiannya kepada guru wali dan BK. 
Seluruh peserta didik SMP IT dan SMA IT Bina Amal otomatis adalah santri pada "pesantren" Bina Amal. Unggulan pada Bina Amal adalah kedisiplinan dan tahfiz atau hafalan al-Qur'an. Al-Qur'an menjadi nilai penting yang diajarkan di Bina Amal. Target kolektif hafalan pada SMP IT adalah 3 juz, sementara pada SMA sebanyak 10 Juz. Pada praktiknya banyak juga yang bisa hafal sampai dengan 30 juz, khususnya pada tingkat SMA.

Pembiasaan hidup Islami juga menjadi ciri di Bina Amal. Dengan sistem asrama menjadikan pembimbingan lebih mudah. Pembiasaan Islami dilakukan di sekolah ini yaitu: salat jemaah, dhuha, tilawah al-Qur'an, hafalan al-Qur'an menjadi habit bagi anak. Nilai kedisiplinan pada sekolah ini juga menjadi penekanan. Selain itu, peminatan juga disesuaikan bakat minat anak. Bakat minat peserta didik ada yang cenderung ke bidang akademik, agama, atau pun olah raga. semua difasilitasi. Terkait olah raga sekolah ini terkenal unggul di bidang basket.

Tabel 2 Program rutin tahfiz di SMIT Bina Amal

\begin{tabular}{l|l|l|}
\hline No & Kegiatan & Waktu \\
\hline 1 & Ziyadah & $\begin{array}{l}\text { Senin - Kamis } \\
07.15-08.20\end{array}$ \\
\hline 2 & Muroja'ah & $\begin{array}{l}\text { Senin - Kamis } \\
18.00-05.45\end{array}$ \\
\hline 3 & Isti'daad & $\begin{array}{l}\text { Senin - Jumat } \\
\text { Sesuai jadwal }\end{array}$ \\
\hline 4 & $\begin{array}{l}\text { Tilawah } \\
\text { mandiri } \\
\text { Tahsin A1- } \\
\text { Qur'an }\end{array}$ & $\begin{array}{l}\text { Setiap waktu } \\
\text { Senin - Kamis } \\
15.30-16.30\end{array}$ \\
\hline 6 & $\begin{array}{l}\text { Test hari } \\
\text { ketuntasan }\end{array}$ & $\begin{array}{l}\text { Setiap hang sudah } \\
\text { dijadwalkan }\end{array}$ \\
\hline
\end{tabular}

Sumber: Dokumen SMIT, 2020

Dari sudut psikologi perkembangan, anak usia SMP/SMA memasuki peka sosial dan personifikasi personal. Di masa itu, hal yang paling menonjol adalah anak memasuki masa pubertas, mengalami kematangan fisik, memiliki kecenderungan berkelompok, kondisi mental kejiwaan labil, dorongan kebebasan kuat, cukup realistik dan mencari figur idola. Kondisi ini menuntut perhatian lebih dari sekolah, orang tua, pemerintah dan masyarakat untuk membantu penumbuhkembangan potensi mereka agar dapat diarahkan kepada aktivitas-aktivitas positif yang berguna bagi masa depan mereka. Pilihan model sekolah berasrama adalah sebuah langkah agar mampu membantu penumbuhkembangan potensi anak secara maksimal.

Sistem sekolah berasrama (boarding school system) menjadi pilihan sebab usia SMP/SMA membutuhkan lingkungan yang kondusif, pembinaan berkelanjutan dan menyeluruh untuk membantu peserta didik mencapai pertumbuhan dan perkembangan ideal sehingga mereka memiliki kesiapan untuk melanjutkan pendidikan jenjang yang lebih tinggi dan menghadapi tantangan masa depannya.

Pembelajaran peserta didik pada SMIT Bina Amal terintegrasi antara kegiatan di sekolah dan kegiatan sebagai santri Bina Amal. Pembagian pada sekolah dibagi berdasarkan jenjang SMP dan SMA. Selain itu, dibagi berdasarkan rombongan belajar masing-masing. Pada kegiatan di asrama, selain mengikuti pembagian sekolah pagi juga dibagi berdasarkan jenis kelamin dan tingkat hafalan Al-Qur'an peserta didik. Pengelompokan dibagi menjadi tiga: hafalan tinggi, sedang, rendah dengan masing-masing kelompok terdiri atas sepuluh peserta didik. Target hafalan masingmasing kelompok beragam.

Kegiatan rutin harian pada SMIT Bina Amal secara umum adalah sebagai berikut:

Tabel 3 Kegiatan Harian

\begin{tabular}{|c|c|c|c|}
\hline No & Waktu & Kegiatan SMP & Kegiatan SMA \\
\hline 1 & $03.00-04.00$ & $\begin{array}{l}\text { QL, Persiapan Shalat } \\
\text { Subuh, Sahur (Senin- } \\
\text { Kamis) }\end{array}$ & $\begin{array}{l}\text { QL, Periapan Shalat } \\
\text { Subuh, Sahur (Senin- } \\
\text { Kamis) }\end{array}$ \\
\hline 2 & $04.00-05.15$ & $\begin{array}{c}\text { Shalat Subuh, Al } \\
\text { Ma'tsurot, dan } \\
\text { tilawah / persiapan } \\
\text { hafalan }\end{array}$ & $\begin{array}{c}\text { Shalat Subuh, } \mathrm{Al} \\
\text { Ma'tsurot, dan tilawah } \\
\text { / persiapan hafalan }\end{array}$ \\
\hline 3 & $05.15-06.30$ & $\begin{array}{l}\text { Kegiatan pribadi } \\
\text { (mandi, makan) }\end{array}$ & $\begin{array}{l}\text { Kegiatan pribadi } \\
\text { (mandi, makan) }\end{array}$ \\
\hline 4 & $06.30-06.45$ & Apel asrama & Apel asrama \\
\hline 5 & $06.45-07.15$ & Perwalian & Perwalian \\
\hline 6 & $07.15-08.30$ & $\begin{array}{c}\text { Tahfizul Quran } \\
(07.15-08.20)\end{array}$ & $\begin{array}{c}\text { Tahfizul Quran (07.15- } \\
07.45) \\
\end{array}$ \\
\hline 7 & $08.30-14.00$ & KBM Kelas & $\begin{array}{c}\text { KBM Kelas (07.45- } \\
14.20)\end{array}$ \\
\hline 8 & $14.00-15.00$ & Kegiatan pribadi & Kegiatan pribadi \\
\hline
\end{tabular}




\begin{tabular}{|c|c|c|c|}
\hline 9 & $15.00-16.30$ & $\begin{array}{l}\text { Shalat Ashar, Al } \\
\text { Ma'tsurat, dan } \\
\text { Tahsin Al Quran }\end{array}$ & $\begin{array}{l}\text { Shalat Ashar, Al } \\
\text { Ma'tsurat,tahsin }\end{array}$ \\
\hline 10 & $16.30-17.30$ & $\begin{array}{c}\text { Kegiatan pribadi } \\
\text { (olahraga, mandi, } \\
\text { makan) }\end{array}$ & $\begin{array}{c}\text { Kegiatan pribadi } \\
\text { (olahraga, mandi, } \\
\text { makan) }\end{array}$ \\
\hline 11 & $17.30-18.00$ & $\begin{array}{l}\text { Persiapan shalat } \\
\text { maghrib, shalat } \\
\text { maghrib }\end{array}$ & $\begin{array}{l}\text { Persiapan shalat } \\
\text { maghrib, maghrib }\end{array}$ \\
\hline 13 & $18.15-19.00$ & $\begin{array}{c}\text { Tilawah/Murojaah } \\
\text { hafalan }\end{array}$ & $\begin{array}{c}\text { Tilawah/Murojaah } \\
\text { hafalan }\end{array}$ \\
\hline 14 & $19.00-19.15$ & Kultum & Kultum \\
\hline 15 & $19.15-19.30$ & $\begin{array}{l}\text { Persiapan KBM } \\
\text { asrama/bimbel }\end{array}$ & $\begin{array}{l}\text { Persiapan KBM } \\
\text { asrama/bimbel }\end{array}$ \\
\hline 16 & $19.30-20.30$ & $\begin{array}{c}\mathrm{KBM} \\
\text { Asrama/Bimbel }\end{array}$ & KBM Asrama/Bimbel \\
\hline 17 & $20.30-21.00$ & Belajar Mandiri & Belajar Mandiri \\
\hline 18 & $21.00-21.30$ & $\begin{array}{c}\text { Mutaba'ah } \\
\text { yaumiyah dan } \\
\text { persipan tidur }\end{array}$ & $\begin{array}{l}\text { Mutaba'ah yaumiyah } \\
\text { dan persipan tidur }\end{array}$ \\
\hline 19 & $21.30-03.30$ & Tidur & Tidur \\
\hline
\end{tabular}

Sumber: Dokumen SMIT, 2020

Banyak program yang telah dibuat asrama Bina Amal meliputi kerja bakti (setiap ahad), jalan santai (setiap 2 pekan hari sabtu), senam bersama (setiap pekan hari sabtu), life skill (setiap Ahad), nonton bareng (film-film motivasi) - setiap malam Ahad, public speaking (setiap jum'at). Program ruhiyah pekanan meliputi puasa senin kamis, qiyamullail berjama'ah (setiap jum'at malam), tilawah QS. Al Kahfi bersama (setiap jum'at pagi), salat Jum'at, infaq jum'at, pemerikasaan kebersihan kuku (setiap jum‘at), dan BPI (Bina Pribadi Islami). Program bulanan meliputi i'tikaf/ mabit (malam Bina Iman dan Takwa), wisata ruhani, ayyamul bidh, lomba kebersihan kamar dan Ujian kenaikan surat. Program semesteran terdiri atas ujian juz, camp Quran semester 1, dan Camp Quran Semester 2. Kegiatan tahunan terdiri atas peringatan Muharram, peringatan Maulid Nabi, peringatan Isra' Mi' raj, pondok Ramadhan, tarhib Ramadhan, peringatan Idul Qurban dan salat gerhana berjamaah.

SMIT Bina Amal mengelompokan pembelajaran santri berdasarkan kemampuan pada dua keahlian yaitu tahfiz al-Qur'an dan jenjang pendidikan. Tahfiz al-Quran terbagi ke dalam dua program yaitu reguler dan takhassus. Pembeda antara program reguler dan takhassus terdapat pada target capaian hafalan. Santri tahfiz al-Quran reguler ditargetkan bisa menghafal alQur'an sebanyak 1 juz dalam setahun, sehingga total 3 juz dalam tiga tahun pendidikan. Sementara santri tahfiz al-Quran program takhassus diharapkan mampu menghafal 5 juz dalam tiga tahun pendidikan.

Seluruh santri baik program tahfiz al-Quran (reguler maupun takhassus) akan memperoleh pengajaran materi akhlak dan Quran Hadits dalam sepekan. Kitab yang digunakan adalah Ta'lim al-Mutaallim. Dasar pengelompokan kelas adalah kemampuan baca al-Qur'an dan jenjang kelas dalam pendidikan formal di SMP, sehingga sistem kelas yang digunakan adalah 7,8,9. Dengan mempertimbangkan jumlah santri pembagian kelas 7,8,9 masing-masing terdiri atas beberapa kelas sesuai dengan hasil placement test. Masingmasing kelas terbagi menjadi tiga kelompok yaitu A, B, dan C. sehingga untuk masing-masing kelas menjadi tiga berdasarkan kemampuan membaca al-Qur'an, sehingga jumlahnya 9 kelompok.

Sistem pengajaran yang digunakan adalah sistem guru kelas. Setiap guru akan mengampu dan mendampingi santri dalam membaca alQur'an dengan penjadwalan yang bersifat rolling. Jumlah seluruh pengajar inti ada enam orang. Sistem rolling ini dilakukan ketika pengajaran waktu Ashar dan Maghrib.

Pola asuh peserta didik pada Integrated Islamic Boarding School Bina Amal Semarang dilakukan secara penuh selama 24 jam. Para pengasuh melakukan pengawasan, bimbingan, disiplin, pemberian hadiah dan hukuman kepada santri dengan penuh kasih sayang. Dengan cara tersebut, pola asuh yang diterapkan SMIT Bina Amal Semarang mirip yang dilakukan di berbagai pondok pesantren.

\section{E. Kesimpulan}

Pola asuh peserta didik pada Integrated Islamic Boarding School Bina Amal Semarang dikelola dengan pola demokratis model pesantren. Seluruh siswa SMIT Bina Amal adalah santri pada "pesantren" Bina Amal. Kepala asrama putra adalah kiai, sementara kepala asrama putri adalah ibu nyai. Pengawasan, bimbingan, disiplin, pemberian hadiah dan hukuman yang diterapkan di Bina Amal Gunung Pati Semarang dilakukan oleh pengasuh beserta organ struktur organisasi yang jelas: korbid budaya Islami dan kedisiplinan, 
korbid tahsin tahfiz, dan korbid akademik. Pengelolaan dibagi menjadi dua yaitu asrama putra dan putri. Demikian juga, struktur organisasi pengasuh terbagi menjadi dua: pengasuh putra dan putri. Aturan disiplin diterapkan secara ketat melalui pedoman pengelolaan peserta didik yang berisi pedoman akademik dan tata kehidupan asrama. Pembelajaran pada SMIT Bina Amal terintegrasi antara sistem sekolah dengan sistem boarding. Peserta didik belajar sepanjang hari, full day and full night. Pembelajaran di asrama dipisah antara santri putra dan santri putri meskipun masih berada dalam satu kompleks.

\section{UCAPAN TERIMA KASIH}

Penelitian ini merupakan bagian dari Tim Penelitian tentang Pola Asuh Peserta Didik pada Satuan Pendidikan Agama dan Keagamaan, yang dilakukan oleh Puslitbang Pendidikan Agama dan Keagamaan, Badan Litbang dan Diklat Kementerian Agama RI. Oleh karena itu, kami mengucapkan terima kasih kepada Kepala Puslitbang Pendidikan Agama dan Keagamaan atas fasilitasi anggaran. Secara praktis, penelitian ini mendapatkan fasilitasi dari Kabid Pendidikan Keagamaan (Husein Hasan Basri) serta ketua tim peneliti (Achmad Dudin) beserta seluruh tim peneliti. Penelitian ini dapat terlaksana karena bantuan dari keluarga besar SMIT Bina Amal Semarang. Oleh karena itu, kami mengucapkan terima kasih. Jazakumullah Ahsanal Jaza. 
Achmad Dudin, M. (2020). Sistem Pengasuhan Santri pada Pesantren Darul Muttaqin Parung Bogor. Penamas, 33, 153-174.

Adawiah, R. (2017). pola asuh orang tua dan implikasinya Terhadap Pendidikan Anak. Jurnal Pendidikan Kewarganegaraan.

Afiati, N. S. (2018). Kualitas Kehidupan Sekolah dan Disiplin pada Santri Asrama Pondok Pesantren. Insight: Jurnal Ilmiah Psikologi. https://doi.org/10.26486/psikologi.v20i1.630

Ali, K. M., Imtihana, A., Ismail, F., \& Zaini, H. (2018). Penerapan Pola Asuh terhadap Santri di Pondok Pesantren Al-Amalul Khair Palembang. Tadrib: Jurnal Pendidikan Agama Islam. https://doi.org/10.19109/ tadrib.v3i2.1797

Dhofier, Z. (1994). Tradisi Pesantren, cet. VI, Jakarta: LP3ES.

Fitriyani, L. (2015). Peran pola asuh orang tua dalam mengembangkan kecerdasan emosi anak. Lentera. https://doi.org/https://doi.org/ 10.21093/lj.v17i1.431

Ibda, H. (2019). Mengkaji Fenomena Mahasantri. Alif.Id. https://alif.id/read/hamidulloh-ibda/ mengkaji-fenomena-mahasantri-b219057p/

Lestari, S. (2014). Penanaman Nilai dan Penanganan Konflik dalam Keluarga. Journal of Chemical Information and Modeling. h t t p s : // d o i.org/10.1017/ CBO9781107415324.004

Muallifah. (2009). Psycho Islamic Smart Parenting. In Yogyakarta: DIVA Press.

Padjrin, P. (2016). Pola Asuh Anak dalam Perspektif Pendidikan Islam. INTELEKTUALITA. https://doi.org/ 10.19109/intelektualita.v5i1.720

Sardiman. (2007). Doc 16. In Interaksi dan Motivasi Belajar Mengajar.

Shochib, M. (1997). Penghampiran Masalah Pendidikan. Jurnal Ilmu Pendidikan. https:// doi.org/10.17977/JIP.V4I2.1089

Sofanudin, A. (2012). Minat Masyarakat terhadap
Model Penidikan Madrasah di Magelang dan Demak. EDUKASI: Jurnal Penelitian Pendidikan Agama Dan Keagamaan. https:// doi.org/10.32729/edukasi.v10i3.170

Sofanudin, A. (2019a). Best Practice Implementasi Kurikulum pada Sekolah Alam Insan Mulia (SAIM) Surabaya. Jurnal SMART (Studi Masyarakat, Religi, Dan Tradisi). https:// doi.org/10.18784/smart.v5i1.744

Sofanudin, A. (2019b). Curriculum Typology of Islamic Religion Education in Integrated Islamic School (SIT). EDUKASI: Jurnal Penelitian Pendidikan Agama Dan Keagamaan. https://doi.org/10.32729/edukasi.v17i1.563

Sofanudin, A. (2021). Kuttab itu Pesantren? Tribun Jateng. Retrieved from https:// jateng.tribunnews.com/2021/05/05/opinikuttab-itu-pesantren\#: :text=Kuttab adalah pesantren tanpa asrama,Islamiyah (KMI) pada Gontor.

Sofanudin, A. dkk. (2019c). Kuttab Diawasi atau Diadopsi. Semarang.

Steenbrink, K. A. (1986). Pesantren, Madrasah, Sekolah: Pendidikan Islam dalam Kurun Moderen. Jakarta: LP3ES.

Suyatno. (2013). Sekolah Islam Terpadu; Filsafat, Ideologi, dan Tren Baru 